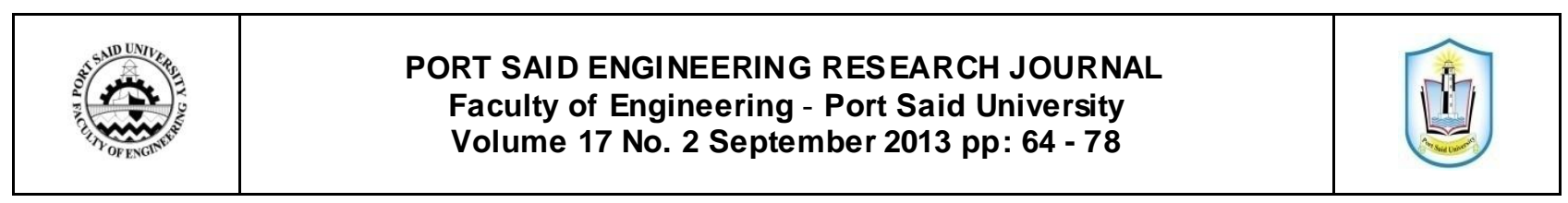

\title{
Effect of Secondary Air Inlet Ports Arrangement on N.G. Flame Combustion Characteristics
}

\author{
Gad, H. M. ${ }^{{ }^{*}}$, Ibrahim A. ${ }^{1}$, A. K. Abd El-Samed ${ }^{1}$ and Farag T. M. ${ }^{1}$
}

\begin{abstract}
The aim of the present work is to investigate theoretically the secondary air ports arrangement on the NG flame combustion characteristics. The normal secondary air was introduced into the combustion chamber through its first half length. Nine different port arrangements are discussed. There are three levels (vertical heights) groups. They are four, eigh $t$ and sixteen levels so that first level of each group starts at $100 \mathrm{~mm}$ that equals $10 \%$ of the combustor len gth. Each group level has four, eight and sixteen ports. Therefore the number of total ports per level is varied from 16 (four levels with fo ur ports) to 256 ( 16 levels with sixteen ports) ports. A theoretical model was used to study the different arrangements. The model consists of a vertical combustor with an air swirler, primary air line, and secondary air and fuel lines. The air swirler number and the primary air to fuel ratio are kept constant for all running conditions and they are 0.87 and 50 , respectively. A three dimensional model was used to simu late the turbulent reacting flow using computational fluid dynamics package (Fluent 6.3). For validation, the comparison between the measured and calculated axial temperature distribution was made and shows a good agreement. A remarkable effect of using the secondary air on temperature maps was found. For any value of SPAR > 0.0, the flame became wider in diameter and longer in length. The flame length increased by about 58, 100 and $125 \%$ when the SPAR increased from 0 to $90 \%$ for the ports arrangement of $4 \times 4,8 \times 8$ and $16 \times 16$ level groups, respectively.
\end{abstract}

KEYWORDS: Gas turbine combustor, Swirling flow, Secondary air, CFD, Co mbustion characteristics, Natural gas

flame.

$\begin{array}{ll}\text { ABBREVIATIONS } \\ \mathrm{A} / \mathrm{F} & \text { Primary air to fuel mass ratio } \\ \mathrm{S} & \text { Primary air swirl number } \\ \mathrm{L} & \text { Combustor length, cm } \\ \mathrm{L}_{\mathrm{f}} & \text { Flame length, cm } \\ \mathrm{L}_{\mathrm{f}} \mathrm{L} & \text { Dimensionless Flame length } \\ \mathrm{SPAR} & \text { Secondary to primary air mass ratio } \\ \mathrm{RFZ} & \text { Reverse flow zone } \\ \mathrm{R}_{\mathrm{i}} & \text { The hub (inner) radius the swirler, } \mathrm{cm} \\ \mathrm{R}_{\mathrm{o}} & \text { The outer radius of the swirler, } \mathrm{cm} \\ \theta & \text { Air swirler vane angle, degree } \\ \mathrm{r} / \mathrm{R} & \text { Dimensionless radial distance } \\ \mathrm{X} / \mathrm{D} & \text { Dimensionless axial distance } \\ \phi_{\mathrm{o}} & \text { Overall equivalence ratio }\end{array}$

\section{INTRODUCTION}

In the economics and industrial considerations, the fuel burning represents the main source of energy in the present time. Studies of combustion characteristics such as in gas turbine combustors focus on exhaust emissions for clean environment, liner wall cooling, uniform exit temperature or exit temperature control and the economical consideration which occurs in fuel saving or fuel economy.

Department of Mechanical Power Engineering, Faculty of Engineering, Port-Said University, Egypt.

"Corresponding author: Hamada_zzdd@yahoo.com
Many operating parameters such as swirl number $(\mathrm{S}=2 / 3$ $\left.\left\{\left[1-\left(\mathrm{R}_{\mathrm{i}} / \mathrm{R}_{\mathrm{o}}\right)^{3}\right] /\left[1-\left(\mathrm{R}_{\mathrm{i}} / \mathrm{R}_{\mathrm{o}}\right)^{2}\right]\right\} \tan \theta\right)$, equivalence ratio, and combustor geometry affect the combustion characteristics; flow field or aerodynamic of flow, flame stability, temperature distributions inside the combustion chamber, flame structure and exhaust species concentrations have been extensively studied [1-13]. The advantages of introducing secondary air are its ability to improve the flame stability, minimize the flame size which leads to minimize the gas turbine combustor size and reducing the exhaust species concentrations [3]. Secondary air has been one of the critical issues in gas turbine combustion chambers. The importance of introducing secondary air to the combustion chambers is depending on the location of the secondary air inlet [3 and 4]. A part of secondary air is used in combustion, it also can be used for cooling the walls of gas turbine combustion chamber and it can be used for flame dilution or control of the exit temperature which affect on the gas turbine blades.

Lee and Moon [11] carried out an experimental investigation of the effects of turbulence generators attached to an axial swirler nozzle on mixing and combustion. A swirler with turbulence generator was designed and manufactured for generating many smallscale eddies in the combustor which contributed to the enhancement of the mixing between fuel and air. The 
mixing in the combustor in the radial direction was significantly improved and flames and temperature were well distributed throughout the cross section of the combustor as the area of turbulence generator increased.

Gad et al [3] studied experimentally the effect of normal secondary air on Kerosene spray combustion characteristics. The experimental results showed that, the flame stability is increased by increasing the air swirl number and SPAR when introducing secondary air with normal direction. The RFZ size is decreased by increasing the secondary to primary air mass flow ratio. Increasing air swirl number and SPAR leads to; decrease in the flame size, increase in the average flame temperature levels and the size of the high temperature region and shift the flame and high temperature region upstream. Increasing the secondary to primary air ratio leads to decrease of $\mathrm{CO}$ and $\mathrm{NO}_{\mathrm{X}}$ concentrations and increase of $\mathrm{CO}_{2}$ concentration.

The effect of secondary air direction on the Kerosene spray combustion characteristics was investigated also by Gad et al [4]. Secondary air was introduced to the combustion chamber in four directions; normal, forward, backward and tangential directions. The experimental results show that, the flame stability is improved by increasing SPAR when introducing secondary air in normal, forward and tangential directions but it is decreased at backward direction. When introducing secondary air, the flame and the high temperature region are shifted upstream and their sizes are decreased. Tangential secondary air gives the shortest flame length. $\mathrm{CO}$ and $\mathrm{NO}_{\mathrm{X}}$ concentrations are decreased by increasing SPAR while $\mathrm{CO}_{2}$ concentration increased

Abd El-Samed [13] studied the natural gas flame characteristics and emissions. A vertical water-cooled combustor tube was designed and manufactured to investigate the stability, the thermal characteristics and exhaust emissions of Natural Gas flame. Adjusting the setting operations of the burners has much greater thermal effects than those of changing the swirl number. The overall heat flux values of outer fuel supply were found to be much greater than those of central fuel supply, for the same swirl numbers of 0.67 to 0.86 .

Nemoda et al [14] investigate experimental and numerically the gaseous fuel combustion in swirl chamber. Mathematical model for prediction of velocity, temperature and concentration fields of axisymmetrical confined swirl turbulent flame was developed. The comparison of the experimental results with computation showed satisfactorily agreement between the model and the experiment. This analysis also showed the importance of the proposed combustion rate model with simultaneous influence of both chemical kinetics and turbulent effects.

The combustion of gaseous fuels in gas turbine combustors is highly complex. It includes hot gas recirculation, energy exchange and strong turbulencechemistry interactions. Therefore, the computational fluid dynamics (CFD) represents an economic and reliable tool for facilitating the combustion system design. Flame stability and pollutant emissions depend on aerodynamics and mixing characteristics of the fuel and combustion air as reported by German and Mahmud [15]. Their results showed good agreement between measurements and predictions by both the $\mathrm{k}-\varepsilon$ model and Reynold Stress model (RSM). However, some features of the combustion flow were better predicted by the RSM model as shown by Jones and Kakhi [16].

From the previous literature review, it is clearly shown that, most of the previous studies experimentally deal with the swirling effect, the mixing process, and introducing secondary air to the combustion chamber. There is not enough data about studying the effect of changing the secondary air inlet ports arrangement on the combustion flame characteristics in a gas turbine combustor model.

In the present work, the effects of the secondary air inlet ports arrangement for constant primary air and swirl number and for different secondary/primary air ratios (SPAR) on natural gas combustion characteristics are theoretically investigated. To validate the calculations, results of the combustion simulation are compared with the experimental data studied by Ibrahim et al [17].

The normal secondary air was introduced into the combustion chamber through its first half length. Nine different port arrangements are discussed. There are three levels (vertical heights) groups. They are four, eight levels and sixteen levels so that first level of each group starts at $100 \mathrm{~mm}$ that equals $10 \%$ of the combustor length. Each group level has four, eight and sixteen ports. Therefore the number of total ports per level is varied from 16 (four levels with four ports) to 256 (16 levels with sixteen ports) ports . Therefore for simple study, the ports arrangements may described by A/B, where A denotes to the number of levels (heights) while B denotes to the number of ports per level.

In the present study, an experimental test rig was constructed to study the validation of the theoretical model. The more details of the experimental test rig can be found in Gad et al [3]. The combustor is simply consists of a vertical combustor of inner diameter and total length of 200 and $1000 \mathrm{~mm}$, respectively. The primary air is sues to the combustor through air swirler around the natural gas nozzle. The secondary air enters the combustor normally and with different levels (height) and ports. The swirl number $(\mathrm{S}=0.87)$ of the used air swirler and the air to fuel mass ratio $(\mathrm{A} / \mathrm{F}=50)$ with constant primary air flow rate are chosen and kept constant during the study.

\section{CFD SIMULATIONS}

CFD software gives the power to simulate flows, heat and mass transfer and chemical reactions [18]. This provides data which help in predicting the performance of the designed model. In this study, the turbulent reacting flow was simulated using the CFD code fluent 6.3 [19]. The model geometries and meshes were generated for each swirl number using Gambit 2.3 [20]. Meshes of tetrahedral cells were created; the mesh has different cell sizes according to the regions of importance. Regions of interest are volumes between swirl vanes, regions near the burner, regions near walls and secondary air inlets as shown in Fig. 1. It shows the complete mesh of the base combustor model 
constructed with swirl vane angles of $45^{\circ}$. Also, the figure shows the details of the important regions such as the swirler and secondary air inlets for normal secondary air inlet. Numerical accuracy can be improved by careful distribution of the grid nodes which offers a good compromise between the computational time and the numerical accuracy.

Boundary conditions were defined as mass flow in let for primary air and fuel and velocity inlet for secondary air, based on the experimental data. The pressure outlet is used with radial equilibrium as an exit boundary condition as shown in Fig. 1. For tetrahedral meshes, the first order discretization scheme is recommended [19] and therefore, it is used in the present study.

Fluent uses a control-volume-based technique to convert a scalar transport equation to an algebraic equation to solve numerically. The flow was assumed to be incompressible and turbulent. A steady state pressure based solver is used to solve the governing equations. In the gradient option, the node-based is selected which is suitable for tetrahedral meshes. The Semi Implicit Method for Pressure Linked Equation algorithm was used for the pressure/velocity coupling which satisfies the mass conservation equation. The pressure staggering option (Presto), is selected for the discretization scheme for pressure. The Presto scheme is available for all mesh types. When using the pressurebased solver, presto is recommended as the discretization method for solving pressure [19].

For turbulence modeling, the shear-stress transport (SST) $\mathrm{k}-\omega$ model in fluent is preferred here because the level of agreement of the results for the SST k- $\omega$ model and the experimental data is better than that for other models. For modeling the reacting flow, the non premixed combustion model is selected. A probability density function (PDF) table was created which contains information on the thermo-chemistry and its interaction with turbulence. Fuel and oxidizer compositions are specified in the PDF table. All thermodynamic data, including density, specific heat, and formation enthalpies are extracted from the chemical database when the non premixed combustion model is used. The P1 model, one of the radiation models available in Fluent package 6.3, is selected for the present simulation which can produce an acceptable solution than other models with the non premixed combustion model.

To obtain a grid-independent solution, the grid should be refined until the solution no longer varies with additional cells. A grid independence test has been carried out, considering the computational expense and time, with cell numbers of 175000, 225000, 300000 and 400000. The solution of the centerline temperature distribution was performed for meshes with different cell sizes. There is a good agreement of the centerline temperature profiles for 300000 and 400000 mesh sizes while there was a higher error in the other cases. Therefore, the mesh size of 300000 cells can provide grid independent and accurate solutions. The grid with 300000 cells is considered for further analysis since the flow parameters are found to be independent of the mesh size. The solution control parameters and under-relaxation factors were properly set.
For evaluating whether convergence has been reached, one method is when the residuals have decreased to a sufficient degree. Each residual will be reduced to a value less than $10^{-3}$ except for energy residual which is reduced to $10^{-6}$.

\section{RESULTS AND DISCUSSION}

\subsection{Validation of the Models}

To validate the used model, the computation model results were compared with the measured ones at same running conditions. The computational and experimental centerline temperature distributions for normal secondary air at swirl number of $0.87, \mathrm{~A} / \mathrm{F}$ ratio of 50 and $\mathrm{SPAR}=1$ are shown in Fig.2. The comparison shows a good and acceptable agreement with maximum error about $8 \%$. It is seen that the temperatures from computations are higher than that from the experiments. This is due to the combustor is cooled with water which absorbs quantitative heat and further heat is lost by convection and radiation [21]. In addition, the use of bare wire thermocouple where its junction does not obtain the same temperature of the combustion gases, the measured temperature is quite far from the calculated one [22]. Generally, it is found that the measured temperature is lower than the calculated one by about 6-8\%.

\subsection{Computation Re sults}

The effect of the secondary air inlet ports arrangement at constant primary air mass flow rate, constant $\mathrm{A} / \mathrm{F}$ ratio, and constant swirl number for different secondary/primary air ratios SPAR on natural gas combustion characteristics is theoretically investigated. The radial and axial dis tributions inside the whole combustor of temperature, $\mathrm{CO}_{2}, \mathrm{CO}$, and $\mathrm{O}_{2}$ concentrations are determined and described by different maps for all the ports arrangements used.

\subsubsection{Effect of SPAR on Temperature Maps}

The effect of secondary/primary air mass ratios, SPAR, on the temperature maps for the three level groups of $4 \times 4$, $8 \times 8$ and $16 \times 16$ ports arrangements at same running conditions are shown in Figs.3-5, respectively. To clarify the effect of using secondary air on NG combustion, the first map drawn in each figure describes the temperature distribution without using the secondary air, SPAR $=0$. A remarkable effect of using the secondary air on temperature maps was found. For any value of SPAR >0.0, the flame became wider in diameter and longer in length. The three figures show that, increasing the SPAR, the flame size became more compact and with longer flame length. The flame length increased by about 58, 100 and $125 \%$ when the SPAR increased from 0 to $90 \%$ for the ports arrangement of $4 \times 4,8 \times 8$ and $16 \times 16$ level groups, respectively.

Increasing the secondary air mass flow rate, at constant primary air flow rate, leads to increase the secondary air velocity and hence its momentum may press and compress the flame and then elongates the flame length, i.e. the flame is stretched. The figures show also that the secondary air 
is sues from the first level ports have more effect than that of the other subsequent ports. The secondary air of the first level ports seems to divide the flame from its first lower part, as shown clearly in the maps particularly at high secondary to primary air ratio.

From figures 3, 4 and 5, it shown that, when the total numbers of ports increased (from $4 \times 4=16$ to $16 \times 16=256$ ports) at same value of SPAR and S, the secondary air inlet velocity decreased and its momentum of secondary air also decreased, hence the sharing of the secondary air decreased that leads to decreasing in the average flame temperatures distribution.

\subsubsection{Effect of Ports Arrangements}

Nine different port arrangements are discussed. There are three levels (vertical heights) groups. They are four, eight levels and sixteen levels so that first level of each group starts at $100 \mathrm{~mm}$ that equals $10 \%$ of the combustor length. Each group level has four, eight and sixteen ports. Therefore the number of total ports per level is varied from 16 (four levels with four ports) to 256 (16 levels with sixteen ports) ports. Therefore for simple study, the ports arrangements may described by $\mathrm{A} / \mathrm{B}$, where $\mathrm{A}$ denotes to the number of levels (heights) while $\mathrm{B}$ denotes to the number of ports per level. Being large of results were gotten, some of them were chosen for discussion and clarify ing the effect of using the secondary air. The 16-level group was chosen with 4,8 and 16 ports for every level. These arrangements are expressed by $16 \times 4,16 \times 8$ and $16 \times 16$ ports arrangements. The effect of these arrangements on the temperature, $\mathrm{CO}_{2}, \mathrm{CO}$, and $\mathrm{O}_{2}$ concentrations maps is shown in Fig. 6 at same SPAR $=60 \%, S=0.87$ and $A / F=50$.

It is shown that from figure 6 , increasing the number of ports per level (the total ports also increases) of 64, 128 and 256 ports, the flame size and length also increases by about 75,75 and $117 \%$, respectively. Increasing the total ports, the is suing velocity decreases and in turn the secondary air momentum also decreases resulting in less sharing in combustion zone. The secondary air entering the combustor from all the ports press and compress the flame and force it to be wider in diameter and longer in length. The concentrations maps of $\mathrm{CO}_{2}, \mathrm{CO}$ and $\mathrm{O}_{2}$ are similar to that of temperatures maps.

The boundary of zero value of $\mathrm{O}_{2}$ from the $\mathrm{O}_{2}$ map can be defined as the chemical flame length where the chemical reaction completed. The effect of the number of ports on the chemical flame length of 4-Level, 8-Level and 16-level arrangements is shown in Fig.7. 16-Level arrangements have the largest effect in increasing the chemical flame length.

\subsubsection{Effect of Total Number of Ports}

The effect of secondary air arrangements having the total ports with different level group on the temperature, $\mathrm{CO}_{2}$, $\mathrm{CO}$, and $\mathrm{O}_{2}$ concentrations maps for 4-Level, 8-Level and 16-Level is shown in Fig.8-10, respectively at same $\mathrm{SPAR}=60 \%, \mathrm{~S}=0.87$ and $\mathrm{A} / \mathrm{F}=50$. The effect of the total ports number has a little effect on all the temperature and concentrations maps. The effect of the first level ports of 4Level, 8-Level and 16-Level is more than of the other subsequent ports one. There is also a slight effect of the same total secondary air found on the chemical flame length as shown in Fig.11.

\section{CONCLUSIONS}

The effect of the secondary air ports arrangement on the NG flame combustion characteristics is theoretically studied by using a three dimensional model. A three dimensional model was used to simulate the turbulent reacting flow using computational fluid dynamics package (Fluent 6.3). The normal secondary air was introduced into the combustion chamber through its first half length. Nine different port arrangements are discussed with three levels (vertical heights) groups. They are four, eight levels and sixteen levels; each level has four, or eight or sixteen ports. Therefore the number of total ports per level is varied from 16 (four levels with four ports) to 256 (16 levels with sixteen ports) ports. The air swirler number and the primary air ratio are kept constant for all running conditions and they are 0.87 and, respectively. From the calculated results the main following conclusions are derived:

1- A remarkable effect of using the secondary air on temperature maps was found. For any value of SPAR $>0.0$, the flame became wider in diameter and longer in length.

2- Increasing the SPAR, the flame size became more compact and with longer flame length. The flame length increased by about 58, 100 and $125 \%$ when the SPAR increased from 0 to $90 \%$ for the ports arrangement of $4 \times 4,8 \times 8$ and $16 \times 16$ level groups, respectively.

3- The secondary air of the first level ports seems to divide the flame from its first lower part, as shown clearly in the maps particularly at high secondary to primary air ratio.

4- The secondary air entering the combustor from all the ports press and compress the flame and force it to be wider in diameter and longer in length. The concentrations maps of $\mathrm{CO}_{2}, \mathrm{CO}$ and $\mathrm{O}_{2}$ are similar to that of temperatures maps.

5- 16-Level arrangements have the largest effect in increasing the chemical flame length.

6- The effect of the first level ports of 4-Level, 8Level and 16-Level is more than of the other subsequent ports one. There is also a slight effect of the same total secondary air found on the chemical flame length.

\section{REFERENCES}

[1] Goebe1, S. G., Abauf, N., Lovett, J. A., and Lee, C. P., "Measurements of Combustor Velocity and Turbulence Profiles," ASME Paper No. 93-GT228, (1993). 
[2] Crocker, D. S., Smith, C. E., and Myers, G. D., "Pattern Factor Reduction in a Reverse Flow Gas Turbine Combustor Using Angled Dilution Jets," ASME Paper No. 94-GT-406, (1994).

[3] Gad H. M., Farag T. M., Abdel-Mageed S. I., Habik S. E. and Ezz-Eldien A. H., "Kerosene Spray Combustion Characteristics in a Swirl Type Combustor with Normal Secondary Air" PSERJ, Vol. 14 No. 2, September 2010, pp. 52-66.

[4] Gad H. M., Farag T. M., Abdel-Mageed S. I., Habik S. E. and Ezz-Eldien A. H., "Effect of Secondary Air Direction on the Kerosene Spray Combustion Characteristics" PSERJ, Vol. 14 No. 2, September 2010, pp. 41-51.

[5] Sharaf O. A., Mikhael N. N., Farag T. M., Abd Elsamed A. K., "Interaction Between Annulus Gaseous Fuel and Dual Air Jets for Vertical Diffusion Flame", PSERJ, Vol.14, No.2, September 2010, pp.88-110.

[6] Ying Huang and Vigor Yang, "Effect of swirl on combustion dynamics in a lean-premixed swirlstabilized combustor", Proceedings of the Combustion Institute 30, 2005, pp. 1775-1782.

[7] Wang Y. and Rutland C.J., "Effects of temperature and equivalence ratio on the ignition of $n$-heptane fuel spray in turbulent flow", Proceedings of the Combustion Institute 30, 2005, pp. 893-900.

[8] Chigier N.A., Progress in Energy and Combustion Science, 4, Oxford, Pergamon Press, 1987 UK.

[9] Claypole T.C. and Syred N., "The Effect of Swirl Burner Aerodynamics on NOx formation" Eighteenth International Symposium on Combustion, 1981, 8, 81-89.

[10] Meier W., Duan X. R., and Weigand P., "Investigations of swirl flames in a gas turbine model combustor II. Turbulence-chemistry interactions", Combustion and Flame 144, 2006, pp. 225-236.

[11] Lee C.W. and Moon S.Y., "An experimental Investigation of the Effects of Turbulence Generators Attached to an Axial Swirler Nozzle on Mixing and Combustion", Aerospace Science and Technology 6, 2002, pp.517-520.

[12] Abd El-Samed A.K., "Effect of Atomizer Helical Passages Design on Flame Performance", Ain Shams Journal of Mechanical Engineering, ASJME, Vol.1, ISSN:1687-8612, April-2009.

[13] Abd El-Samed A.K., "Natural Gas Flame Characteristics and Emissions", Port-Said Engineering Research Journal, Vol.14, No.1, pp.137-152, March 2010.
[14] Nemoda S., Vukman B., Simeon O., Goran Z., and Nenad C., "Experimental and numerical investigation of gaseous fuel combustion in swirl chamber", International Journal of Heat and Mass Transfer 48, 2005, pp. 4623-4632.

[15] German A. and Mahmud T., "Modeling of nonpremixed swirl burner flows using a Reynoldsstress turbulence closure", Fuel 84, 2005, pp. 583594.

[16] Jones WP and Kakhi M., "Pdf modeling of finiterate chemistry effects in turbulent non-premixed jet flames". Combust. Flame 115, 1998, pp. 210-219.

[17] Ibrahim A., Nasser Shelil, EZZ El-Dien A. H., Mosleh M. and Farag T. M., "Experimental and Theoretical Study of the Effect of Secondary Air Direction on Natural Gas Diffusion Flame", PSERJ, Vol. No.2, 2011.

[18] Falcitelli M., Pasini S. and Tognotti L., "Modelling practical combustion systems and predicting $\mathrm{NOx}$ emissions with an integrated CFD based approach", Computers and Chemical Engineering 26, 2002, pp. 1171-1183

[19] Fluent Program User Guide, Septe mber (2007).

[20] Gambit Program User Guide, September (2007).

[21] Farag T. M., "A study of atomized premixed flame structure", M. Sc. thesis, Cairo university, 1977.

[22] Fawzy El-Mahallawy and Saad El-Din Habik "Fundamental and technology of combustion", El Sevier Science Ltd First edition, 2002. 

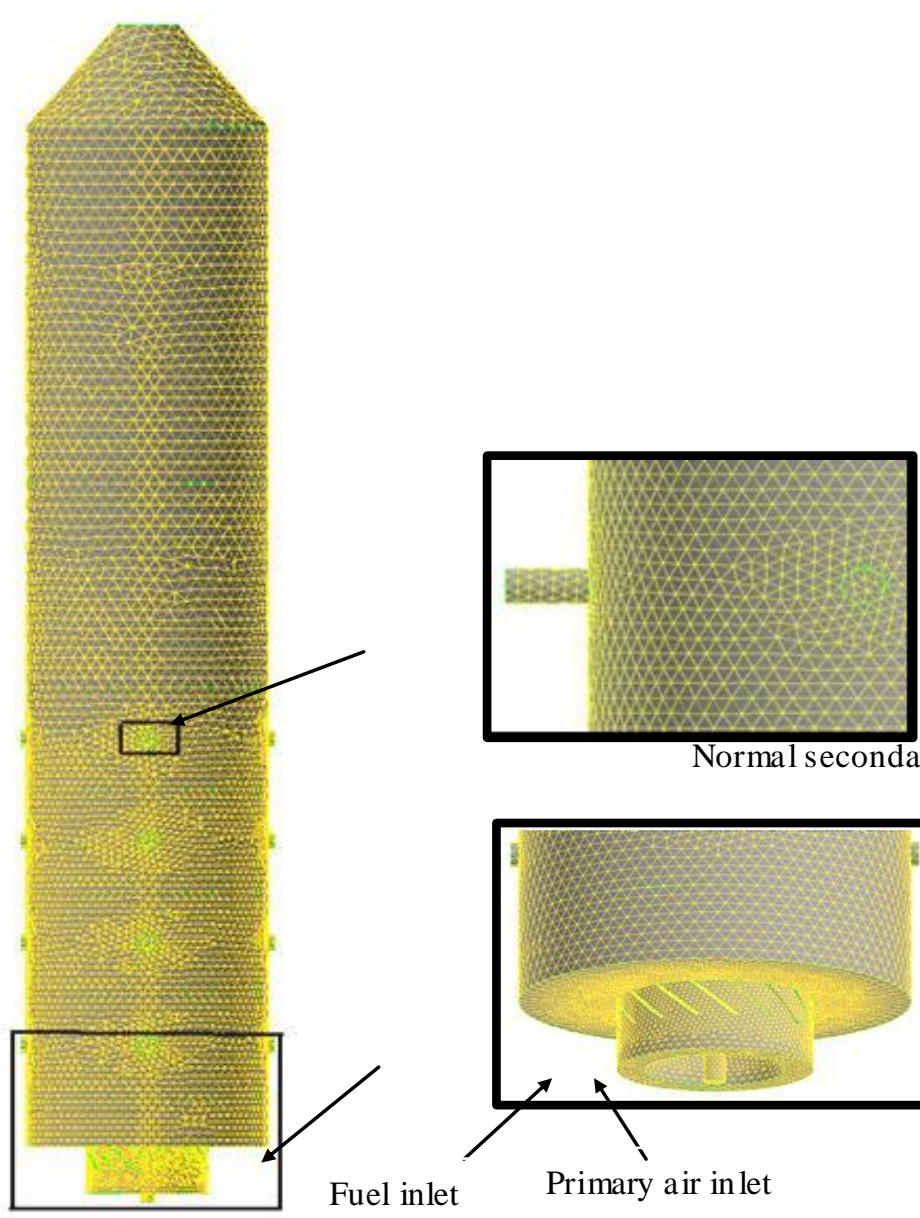

Normal secondary air

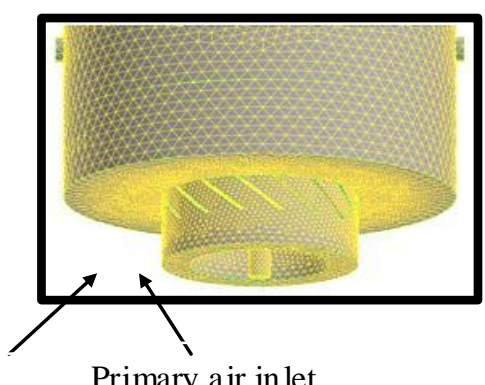

Base combustor grid

Fig. 1 Computational grids of the combustor model

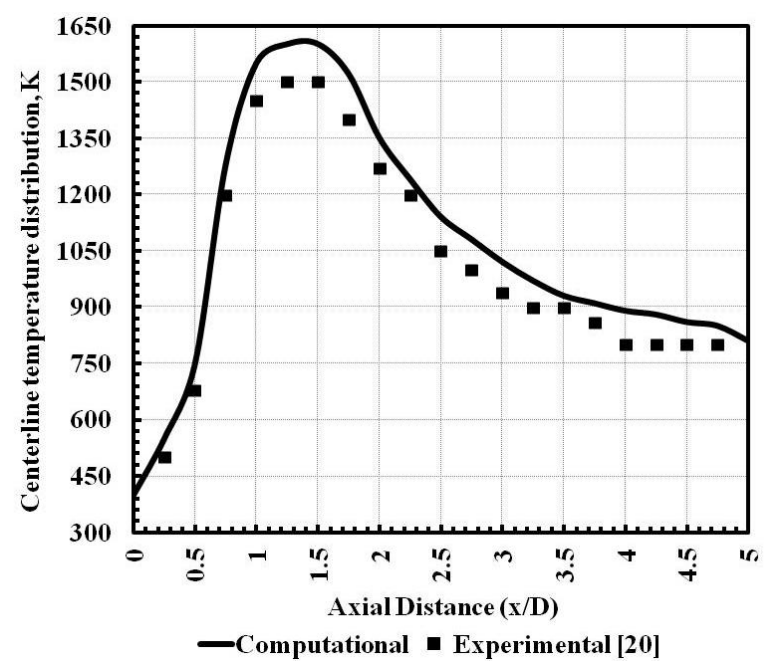

Fig. 2 Variation for the model, Centerline temperature distributions at $\mathrm{S}=0.87, \mathrm{~A} / \mathrm{F}=\mathbf{5 0}, \mathrm{SPAR}=1$ and No. of ports = $16(4 \times 4)$ [Computational and Experimental] 

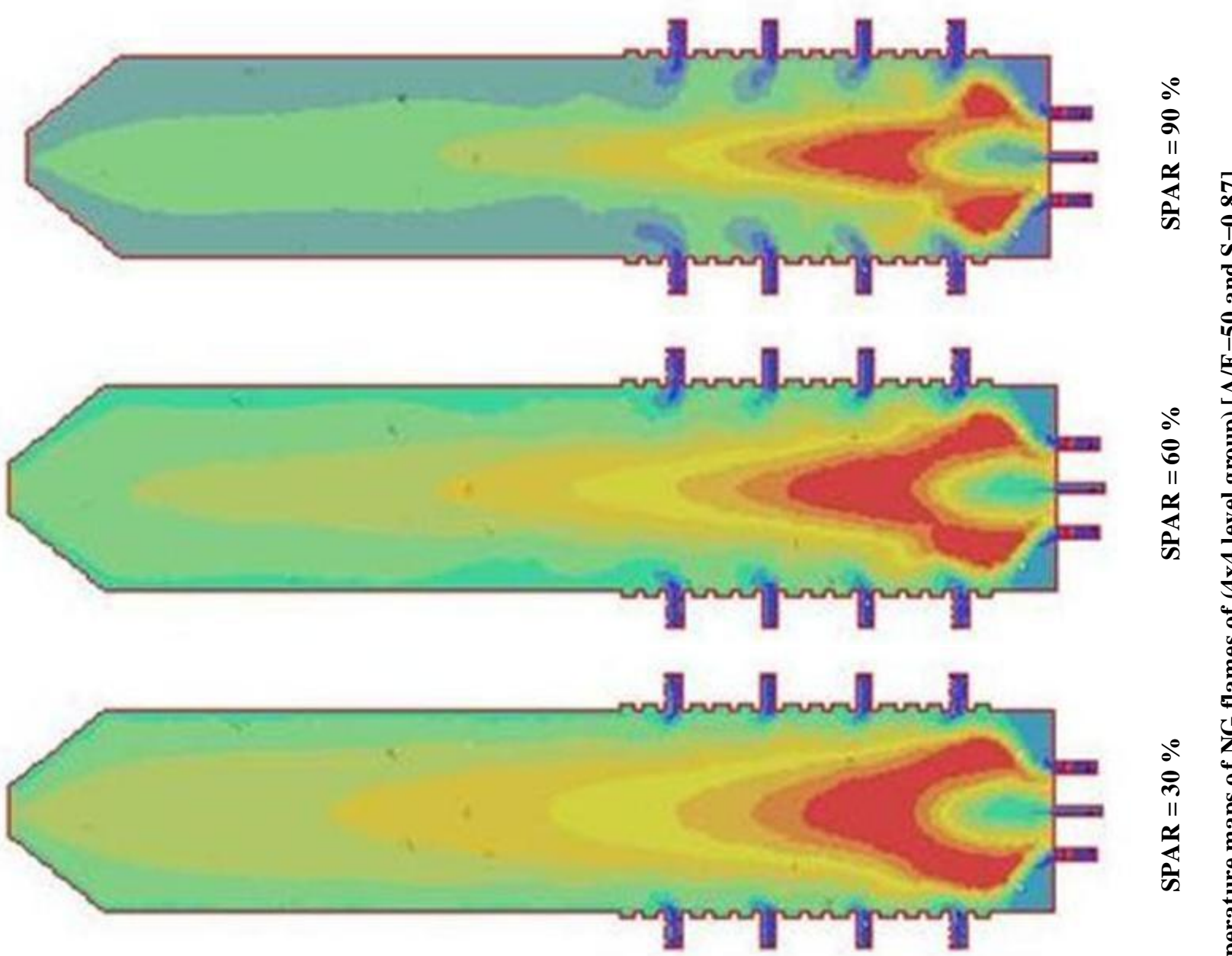

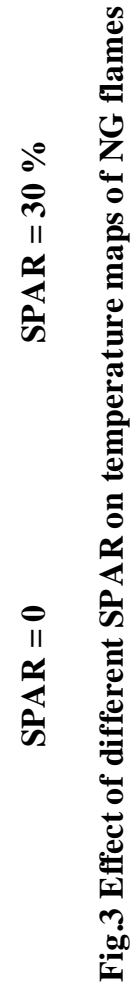

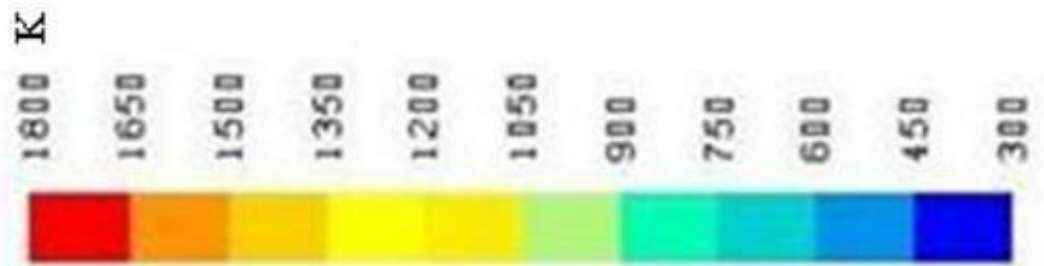


M. Wh-nhth

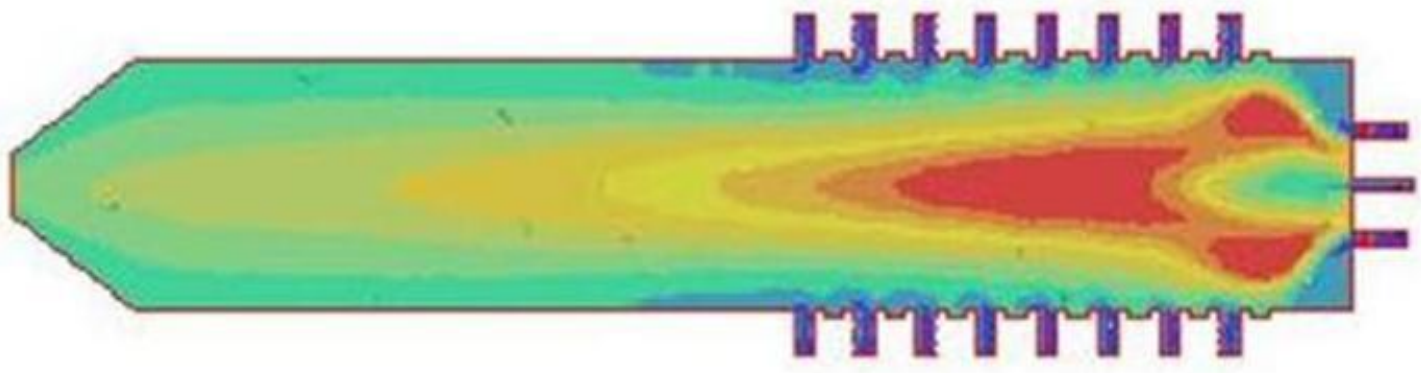

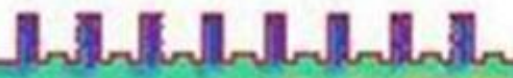

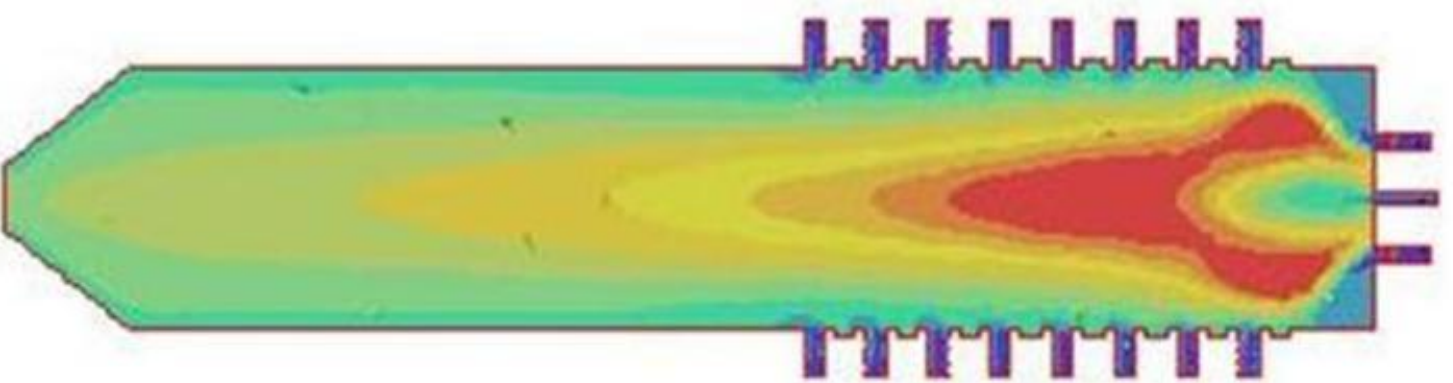

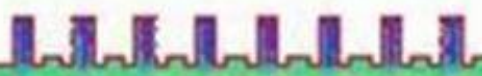

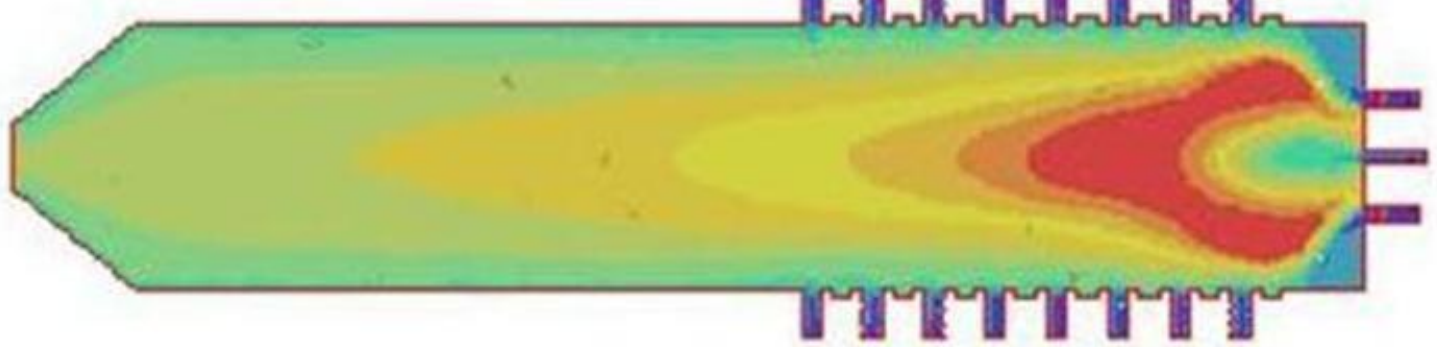

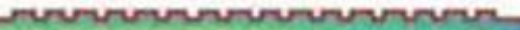

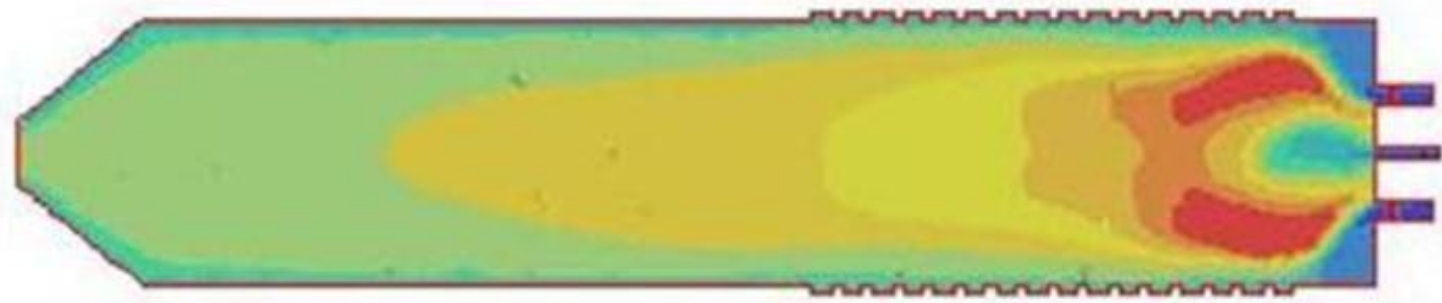

4

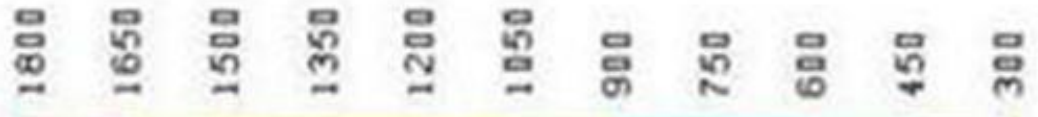




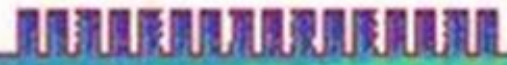

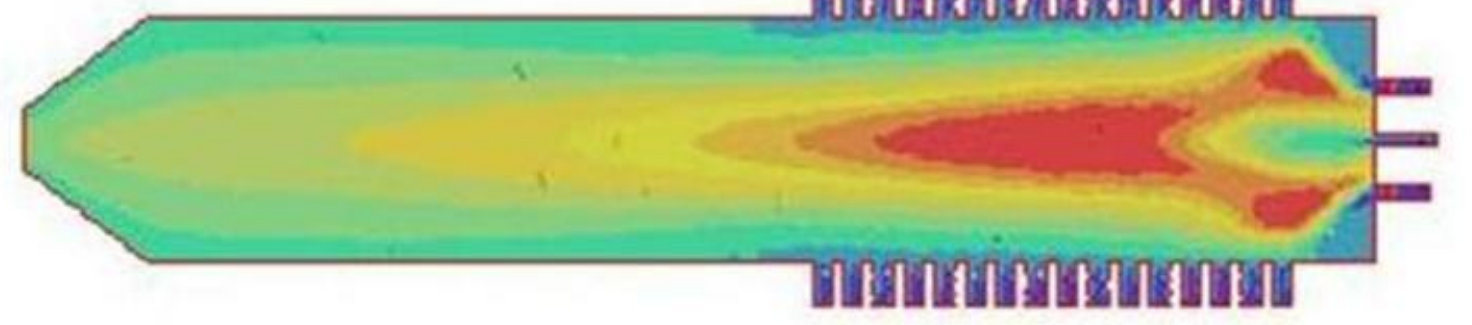

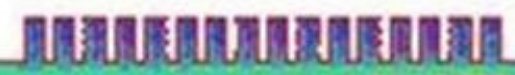

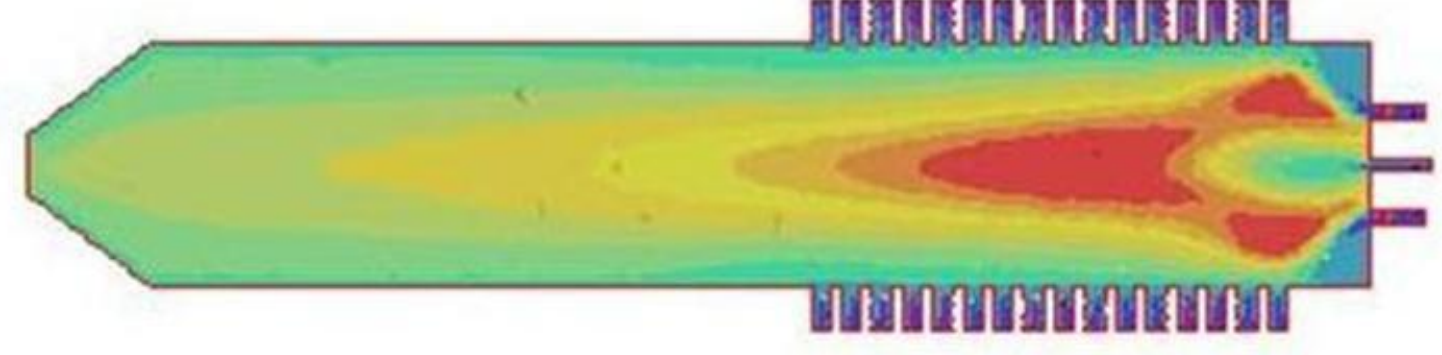

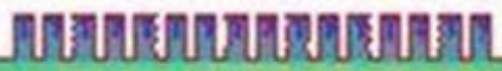
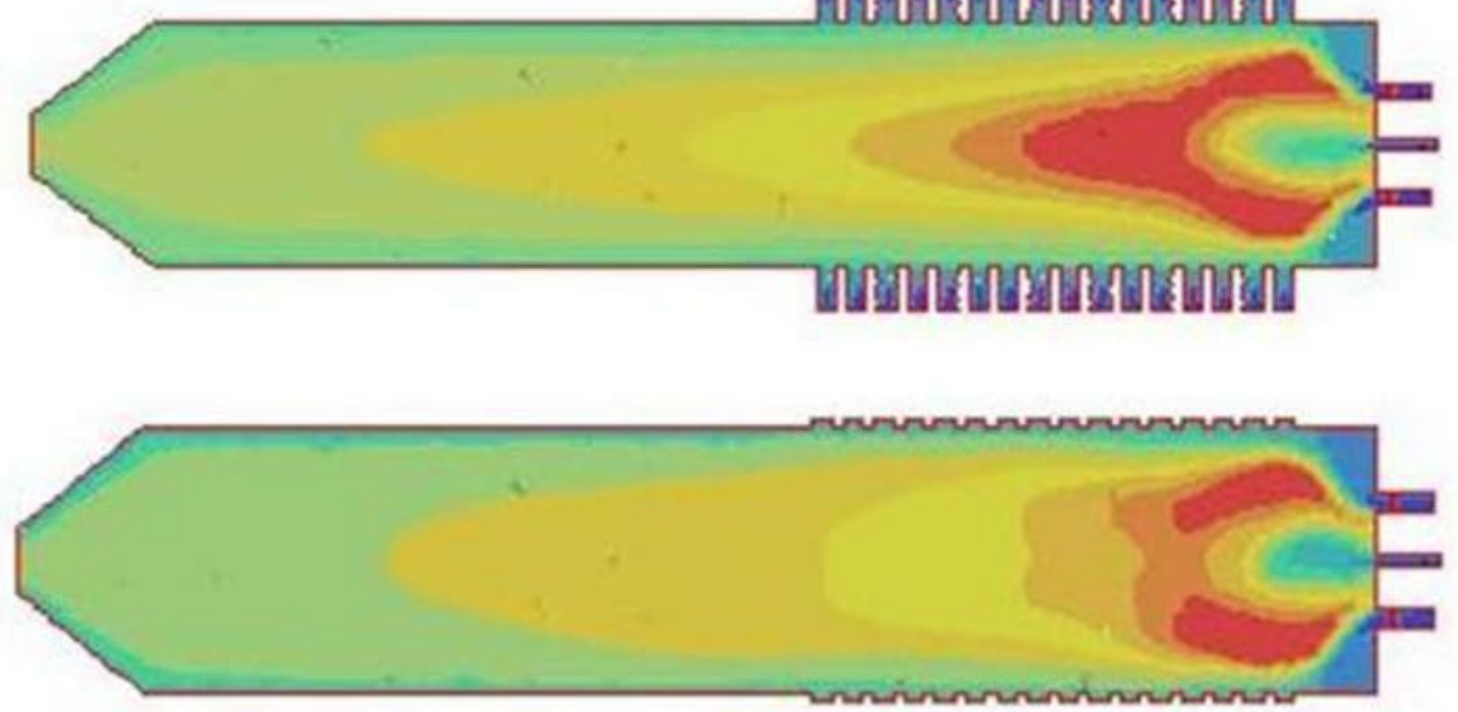

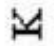

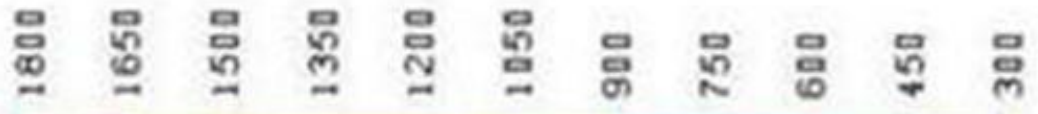




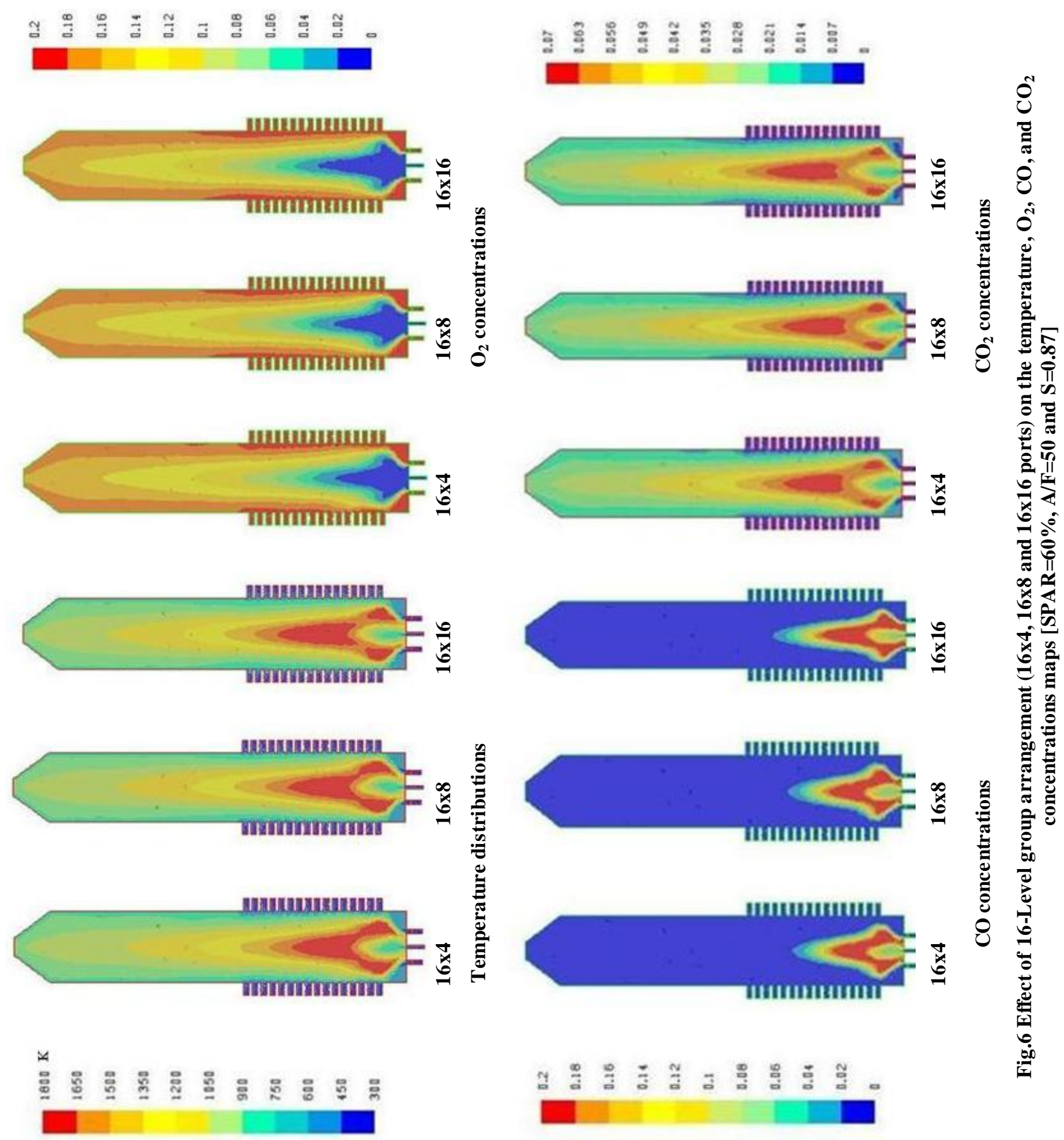




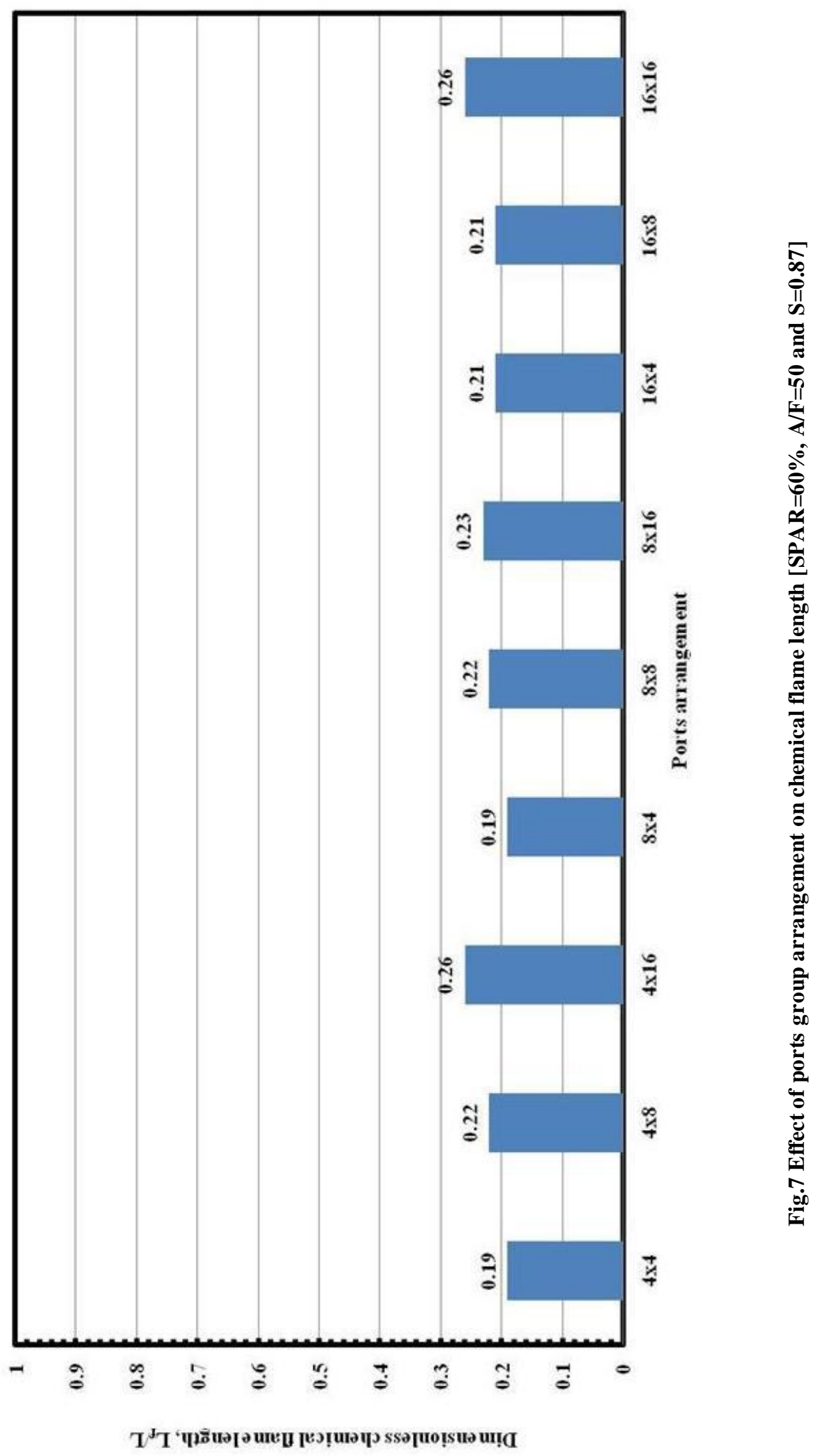




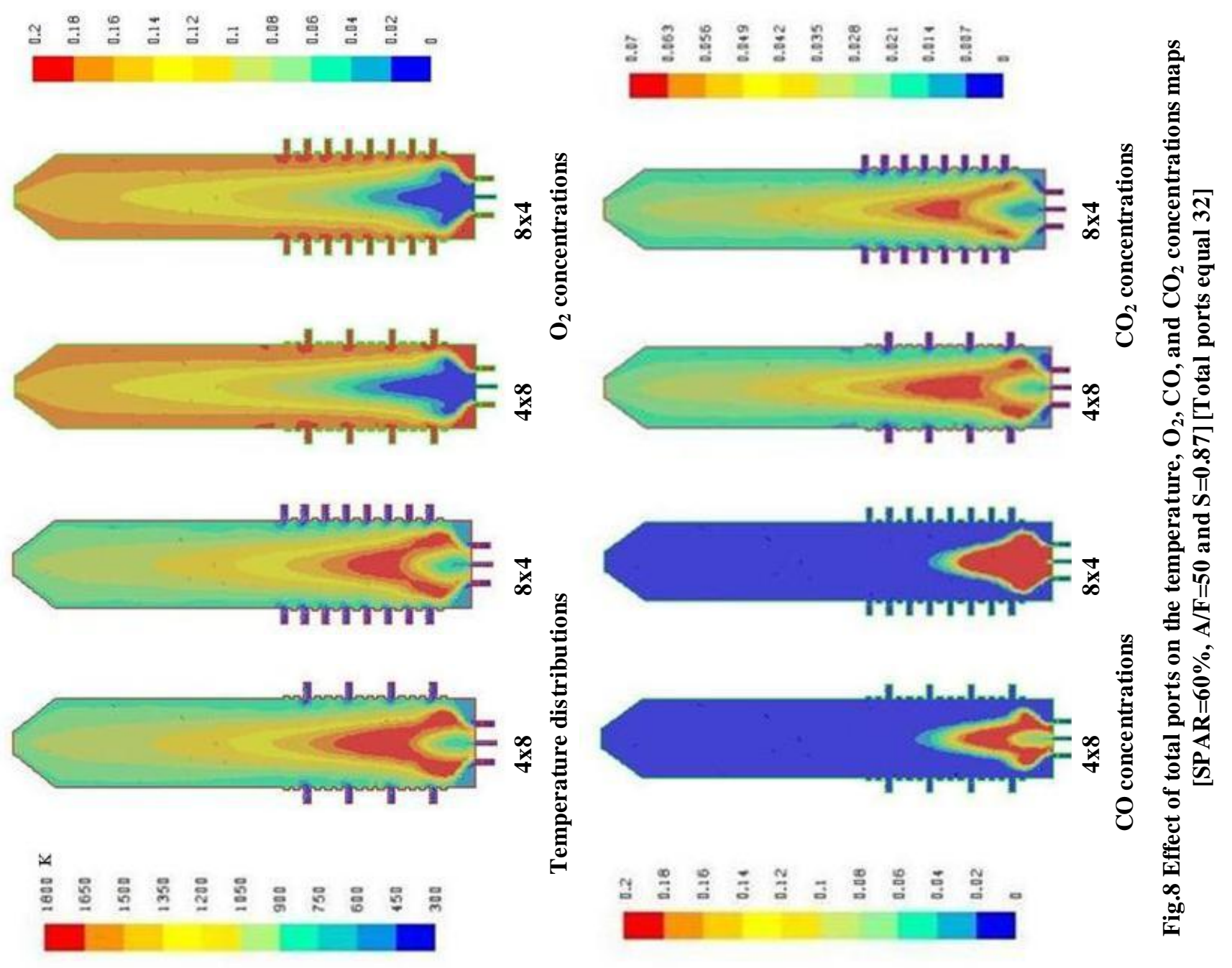




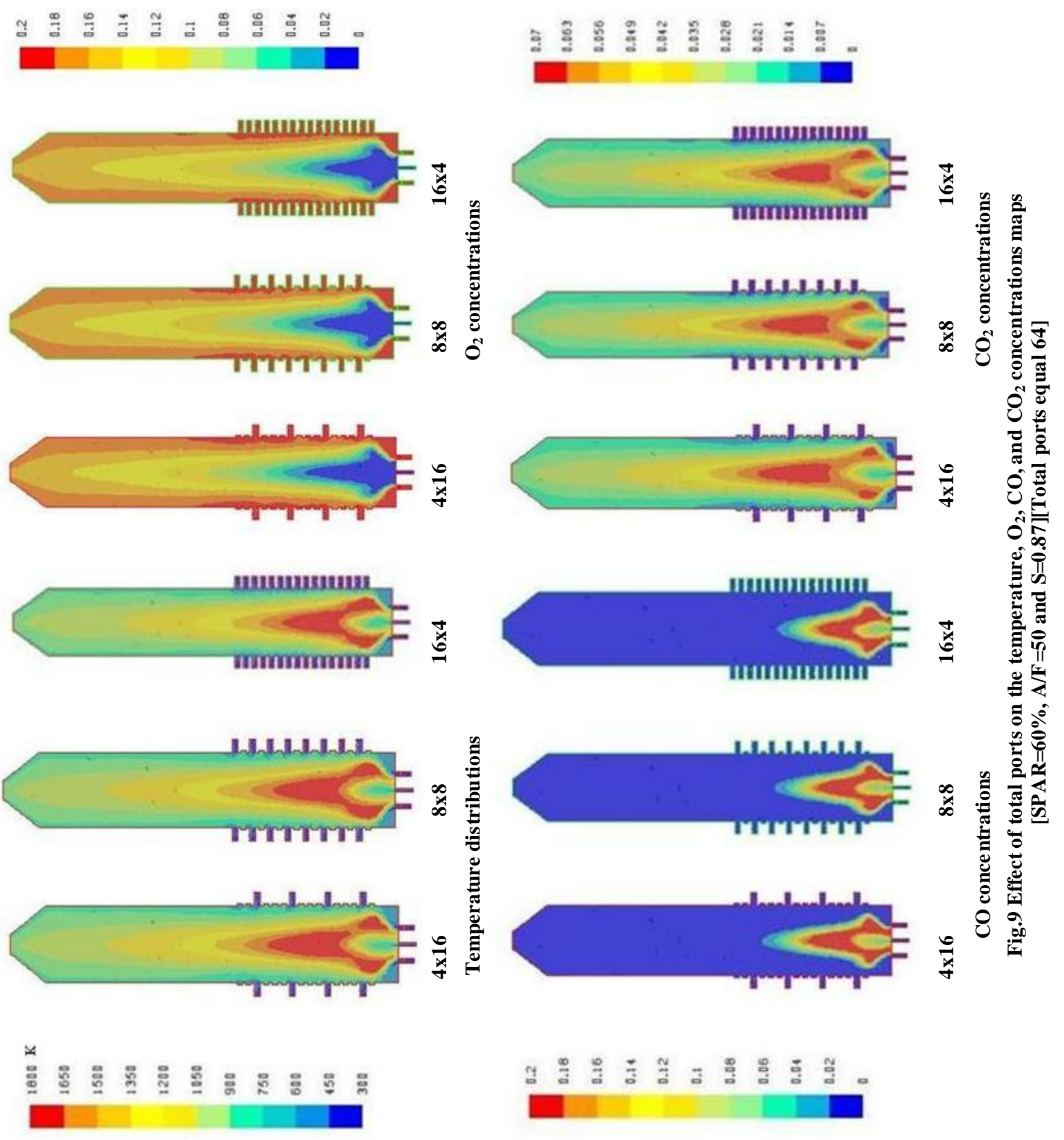



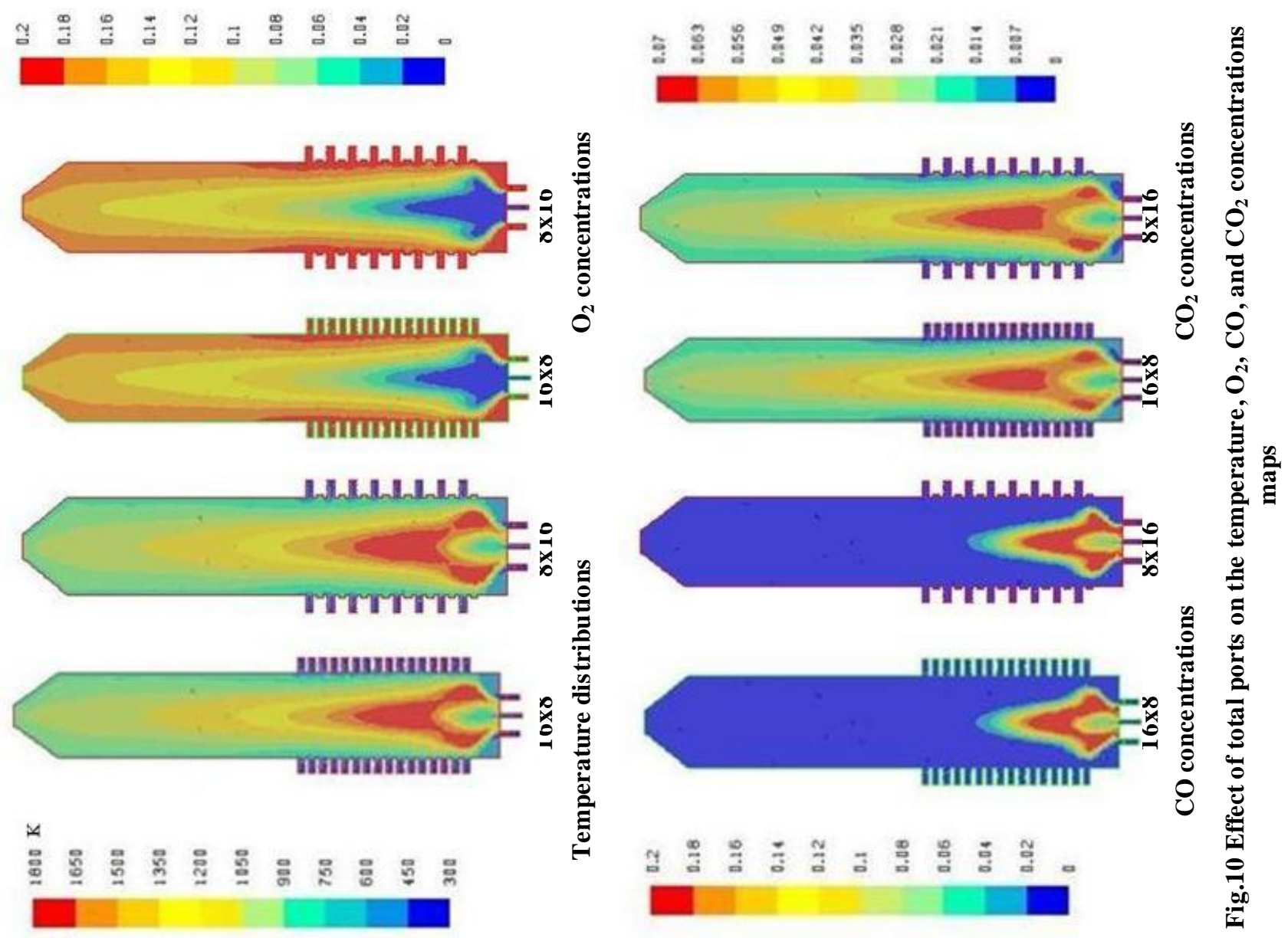


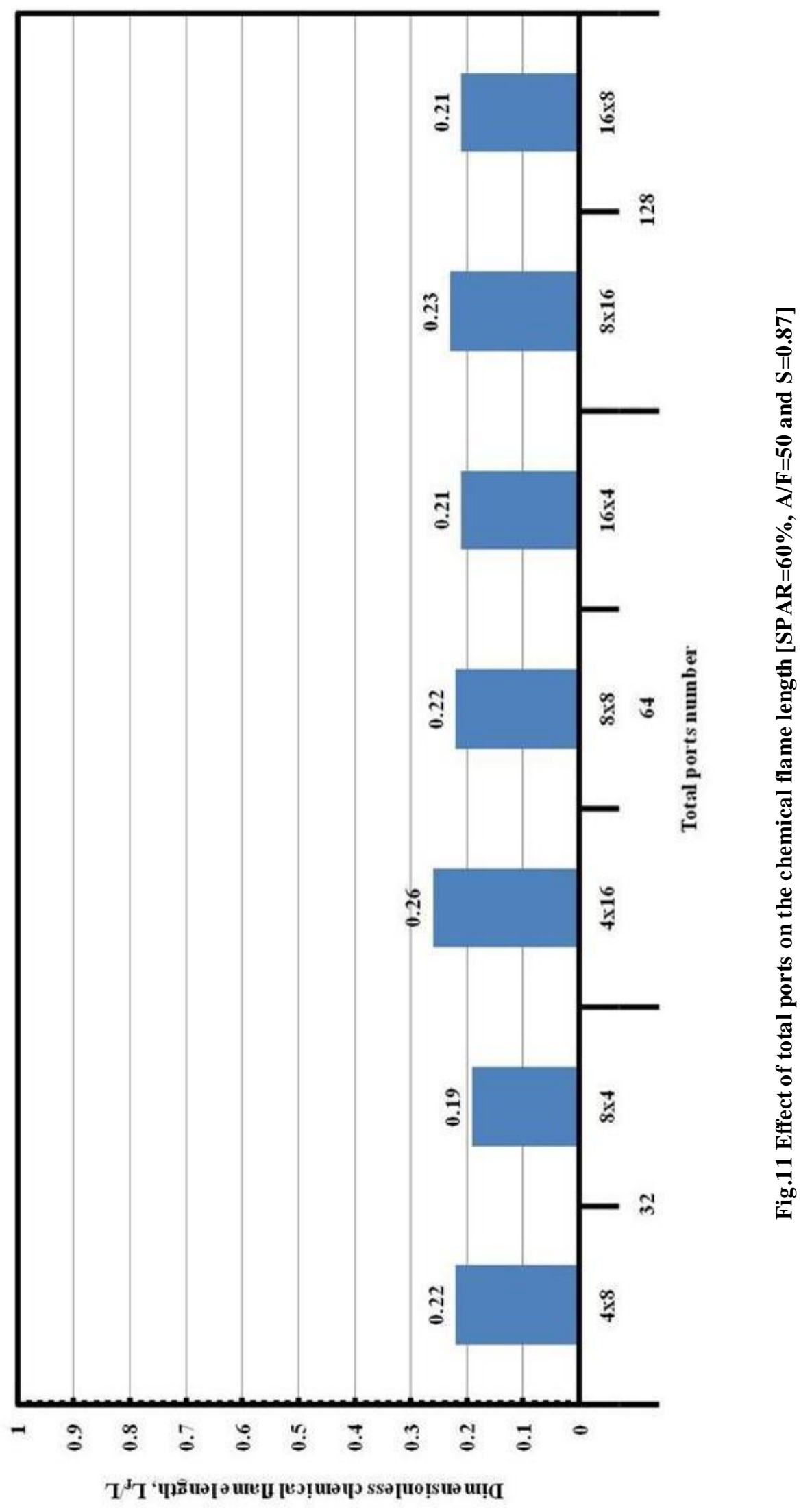

